\title{
TINJAUAN PEMANFAATAN DATA SENSUS HARIAN RAWAT INAP DI RUMAH SAKIT UMUM MUHAMMADIYAH KABUPATEN PONOROGO
}

\author{
Hiskia Yanuarius Numberi \\ @ hiskianumberi.gmail.com \\ STIKES Buana Husada Ponorogo
}

\begin{abstract}
The patient census is an activity that is routinely carried out in the hospital, there are 2 patient censuses, namely a daily outpatient census and a daily inpatient census. Purpose of the Research To find a general description of the use of daily census data for hospitalization in Muhammadiyah General Hospital, Ponorogo Regency. This type of research is descriptive using observation and interviews. The population in this study were the medical record reporting unit analysis officers and the use of inpatient daily census medical record data. In this study, the technique used was accidental sampling, namely using cases or respondents who happened to be there (available somewhere). Data were analyzed descriptively. Based on the results of research at the General Hospital of Muhammadiyah Ponorogo Regency, the use of daily census data for inpatient care was not optimal due to lack of discipline in filling in inpatient daily censuses and no instructions for filling in inpatient daily censuses. Suggestions from researchers are that inpatient / ward staff should enter data correctly so that analysis officers can use daily census data to be used as a data source and facilitate reporting of inpatient service indicators.
\end{abstract}

Keywords: Utilization of Daily Inpatient Census Data

\section{PENDAHULUAN}

Pembangunan ilmu pengetahuan kesehatan saat ini telah mengalami kemajuan seiring dengan berkembangnya berbagai studi cabang Ilmu kesehatan, salah satunya yaitu ilmu rekam medis yang berfungsi sebagai tolak ukur guna menertibkan proses administrasi pada setiap fasilitas pelayanan kesehatan tingkat strata hingga paripurna.

Menurut Permenkes No. 147 Tahun 2010 tentang Perizinan Rumah sakit bahwa Rumah Sakit adalah institusi pelayanan kesehatan yang menyelenggarakan pelayanan perorangan secara paripurna yang menyediakan pelayanan rawat inap, rawat jalan dan gawat darurat. Sedangkan Menurut Permenkes No. 1171/menkes/per/VI/2011 tentang sistem informasi rumah sakit bahwa sesuai ketentuan Pasal 52 ayat (1)
Undang-Undang Nomor 44 Tahun 2009 tentang Rumah Sakit, setiap rumah sakit wajib melakukan pencatatan dan pelaporan tentang semua kegiatan penyelenggaraan rumah sakit dalam bentuk sistem informasi manajemen rumah sakit.

Sistem informasi manajemen rumah sakit termasuk di dalamnya sistem informasi rekam medis, yang menghasilkan laporan-laporan statistik yang informatif sehingga dapat digunakan oleh manajemen rumah sakit untuk pengambilan keputusan, untuk melakukan penilaian pelayanan rumah sakit, serta menilai tingkat keberhasilan atau memberikan gambaran tentang keadaan pelayanan di rumah sakit. Laporan statistik rumah sakit diperoleh dari data sensus harian rawat inap sebagai sumber data. 
Sensus harian rawat inap di Rumah Sakit Umum Muhammadiyah Ponorogo , berasal dari setiap pasien yang datang untuk rawat inap setelah melakukan pendaftaran dan masih tersedia ruang rawat inap yang dimaksud, petugas akan mengantar pasien beserta data rekam medisnya ke ruang rawat tersebut. Pasien diterima oleh petugas ruang rawat inap dan dicatat pada buku register rawat inap. Sensus harian rawat inap dikirim oleh petugas bangsal ke bagian rekam medis dengan menggunakan buku ekspedisi. Petugas pelaporan di bagian rekam medis melakukan rekapitulasi data sensus harian rawat inap untuk selanjutnya diolah dan dihasilkan indikator rawat inap (BOR, LOS, TOI, BTO, NDR, GDR). Setelah itu petugas rekam medis melaporkan ke direktur rumah sakit beserta jajarannya untuk digunakan dalam proses pengambilan keputusan.

Berdasarkan Studi Pendahuluan pada tanggal 5 Januari 2019 di Rumah Sakit Umum Muhammadiyah Ponorogo, dapat di ketahui pemanfaatan data sensus harian rawat inap sebagai acuan pelaporan di unit Indexing dan Reporting, belum digunakan secara maksimal dikarenakan lembar sensus harian dalam jangka waktu satu bulan terdapat $20 \%$ sensus harian rawat inap yang tidak diisi secara lengkap seperti nama ruang, hari keperawatan dan keterangan pulang, yang seharusnya diisi lengkap oleh perawat, karena perawat terkadang lupa mengisi, kewalahan dan kelebihan beban kerja karena banyaknya jumlah pasien rawat inap, akibatnya di bagian analising reporting mengalami kendala dalam pemanfaatan data sensus harian untuk pembuatan laporan.

Upaya yang dapat dilakukan rumah sakit adalah perlu diadakannya sosialisasi petunjuk teknis penulisan/pengisian dan penekanan terkait prosedur tetap tentang Sensus Harian Rawat Inap untuk petugas rawat inap utamanya perawat dalam mekanisme pelaksanaannya. Sehingga pembuatan, penyerahan, perekapan, Sensus Harian Rawat Inap dilaksanakan petugas setiap hari dan sesuai keadaan aslinya agar tidak perlu lagi melengkapi sensus dan tidak menambah beban kerja petugas, sesuai kebijakan Rumah Sakit dan prosedur tetap yang ada.

Berdasarkan latar belakang tersebut, peneliti tertarik untuk mengambil judul Tinjauan Pemanfaatan Data Sensus Harian Rawat Inap di Rumah Sakit Umum Muhammadiyah Ponorogo.

\section{METODE PENELITIAN}

\section{1) Desain Penelitian}

Desain Penelitian adalah kerangka kerja atau cara ilmiah yang digunakan untuk mendapatkan data dengan tujuan dan kegunaan tertentu (Sugiyono, 2016). Jenis penelitian ini merupakan penelitian deskriptif yaitu penelitian yang dilakukukan untuk mengetahui dan menggambarkan objek yang diteliti, mengetahui nilai variabel baik satu variabel atau lebih tanpa menggabungkan atau membandingkannya (Sugiyono, 2016).

Penelitian ini diajukan untuk mengetahui dan memperoleh gambaran tentang pemanfaatan data sensus harian rawat inap untuk pelaporan indikator pealayanan rawat inap di Rumah Sakit Umum Muhammadiyah Ponorogo. Dalam mengumpulkan dan mengungkapkan berbagai masalah dan tujuan yang hendak dicapai maka, penelitian ini dilakukan dengan pendekatan retrospectif yaitu penelitian pada tingkat penggunaan dokumen rekam medis (berdasarkan data masa lampau) (Arief.M 2003).

\section{2) Waktu dan Tempat Penelitian}

Waktu penelitian akan

dilaksanakan pada bulan Desember 2018 sampai dengan Juli 2019 sesuai dengan jadwal penelitian terlampir. Tempat penelitian ini dilaksanakan di Rumah 
Sakit Umum Muhammadiyah Ponorogo JL.Diponegoro No.50,Ponorogo.

\section{3) Kerangka Kerja Penelitian}

Kerangka kerja penelitian adalah kerangka yang menyatakan tentang urutan langkah-langkah dalam melaksanakan penelitian. Kerangka kerja pada penelitian ini adalah sebagai berikut:

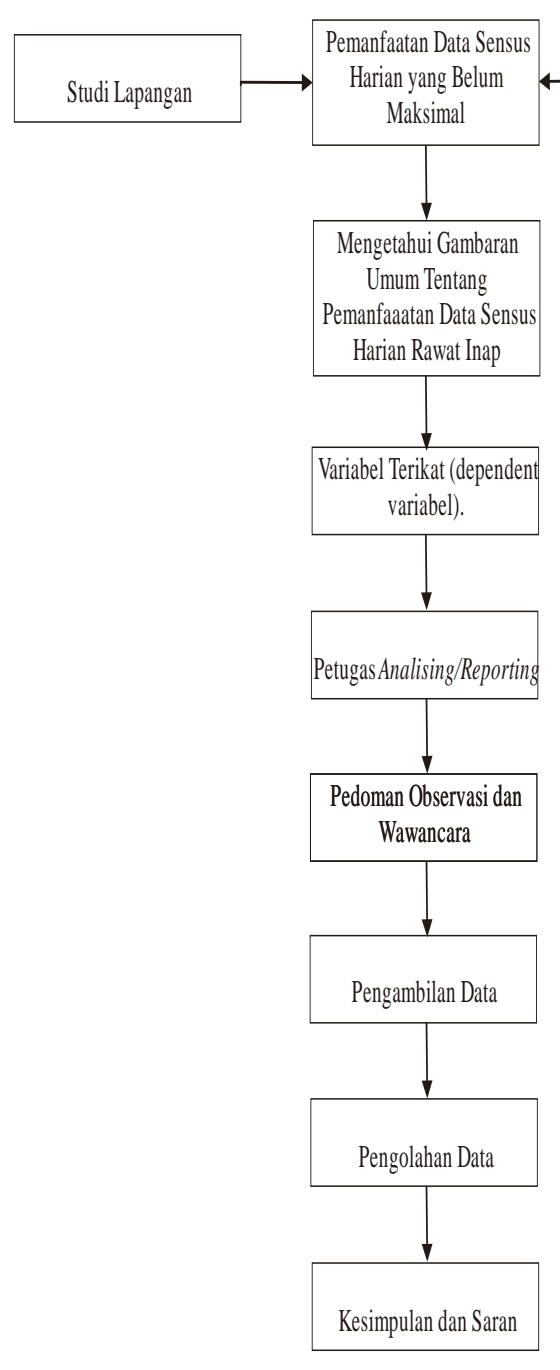

Gambar 1 Kerangka Kerja Tinjauan Pemanfaatan Data Sensus Harian Rawat
Inap Di Rumah Sakit Umum Muhammadiayah Ponorogo

\section{4) Populasi dan Sampel}

1) Populasi

Sugiyono (2016) mendefinisikan populasi adalah suatu obyek atau subyek yang memiliki kualitas dan karakteristik tertentu yang ditetapkan oleh peneliti untuk dipelajari dan kemudian menghasilkan kesimpulan. Populasi pada penelitian ini adalah petugas analising reporting unit rekam medis dan mekanisme pemanfaatan data rekam medis sensus harian rawat inap Rumah Sakit Umum Muhammadiyah Ponorogo.

2) Sampel

Sampel Penelitian adalah sebagian

dari populasi yang mewakili suatu populasi (Sugiyono, 2016). Sampel merupakan bagian dari populasi yang dijadikan subyek penelitian. Sampel yang akan diteliti pada penelitian ini adalah petugas analising/reporting unit rekam medis Rumah Sakit Umum Muhammadiyah Ponorogo.

\section{5) Teknik Sampling}

Teknik sampling adalah teknik pengambilan yang akan digunakan dalam penelitian (Sugiyono, 2016). Pada penelitian ini teknik yang digunakan adalah accidental sampling yaitu menggunakan kasus atau responden yang kebetulan ada (tersedia di suatu tempat). Menurut Notoadmojo (2010), kriteria tehnik sampling yaitu sebagai berikut

1) Kriteria inklusi adalah kriteria atau ciri-ciri yang harus dipenuhi oleh setiap anggota populasi yang dapat diambil sebagai sampel meliputi:

a. Petugas analising/reporting yang bekerja di Rumah Sakit Muhammadiyah Ponorogo 


\section{Jurnal Delima Harapan 2020}

b. Petugas analising/reporting yang sudah pernah menggunakan data sensus harian untuk pelaporan.

c. Lembar sensus harian yang telah diisi perawat.

2) Kriteria ekslusi adalah ciri-ciri anggota populasi yang tidak dapat diambil sebagai sampel meliputi:

a. Petugas rekam medis yang bertugas di bagian assembling.

\section{6) Identifikasi Variabel}

Variabel penelitian ini hanya terdiri dari satu variabel yaitu variabel dependent (terikat) karena hanya ada satu variabel. Variabel terikat sering disebut sebagai variabel output, kriteria atau konsekuen (Sugiyono, 2016).

Variabel terikat dari penelitian ini adalah tinjauan pemanfaatan data sensus harian rawat inap di Rumah Sakit Umum Muhammadiyah Ponorogo.

\section{7) Definisi Operasional}

Definisi operasional adalah suatu definisi yang mempunyai arti tunggal dan diterima secara objektif bilamana indikator ini tidak tampak. Suatu definisi mengenai variabel yang dirumuskan berdasarkan karakteristik variabel yang diamati (Sugiyono, 2016)
Tabel 1 Definisi operasional

$\begin{array}{lll}\text { Variabel Definisi } & \text { Parameter } & \text { Alat } \\ & & \text { Ukur }\end{array}$

\begin{tabular}{|c|c|c|c|c|}
\hline $\begin{array}{l}\text { Tinjauan } \\
\text { Pemanfa } \\
\text { atan Data } \\
\text { Sensus } \\
\text { Harian } \\
\text { Rawat } \\
\text { Inap }\end{array}$ & $\begin{array}{l}\text { Pemanfa } \\
\text { atan data } \\
\text { sensus } \\
\text { harian } \\
\text { rawat } \\
\text { inap } \\
\text { adalah } \\
\text { proses, } \\
\text { cara dan } \\
\text { perbuata } \\
\text { n yang } \\
\text { menjadik } \\
\text { an data } \\
\text { medis } \\
\text { memiliki } \\
\text { nilai } \\
\text { guna } \\
\text { atau } \\
\text { faedah } \\
\text { untuk } \\
\text { digunaka } \\
\text { n dan } \\
\text { dilaporka } \\
\text { n seperti } \\
\text { indikator } \\
\text { pelayana } \\
\text { n, jumlah } \\
\text { sarana } \\
\text { dan } \\
\text { prasarana }\end{array}$ & 4. & $\begin{array}{l}\text { Kelengka } \\
\text { pan dan } \\
\text { ketepatan } \\
\text { data } \\
\text { sensus } \\
\text { harian } \\
\text { rawat inap } \\
\text { meliputi: } \\
\text { a. Nama } \\
\text { Ruang } \\
\text { b. Tangg } \\
\text { al } \\
\text { c. Diagn } \\
\text { osa } \\
\text { d. Ketera } \\
\text { ngan } \\
\text { pulang } \\
\text {. } \\
\text { BPPKM } \\
\text { SOP } \\
\text { Data Base }\end{array}$ & $\begin{array}{l}\text { Obser } \\
\text { vasi } \\
\text { dan } \\
\text { wawa } \\
\text { ncara }\end{array}$ \\
\hline
\end{tabular}

\section{8) Instrumen Penelitian}

Instrumen penelitian adalah alat atau fasilitas yang digunakan oleh peneliti dalam mengumpulkan data agar pekerjaannya lebih mudah dan hasilnya lebih baik, dalam arti lebih cermat, lengkap dan sistematis sehingga mudah diolah (Sugiyono, 2016). Dalam penelitian ini, 
instrumen yang digunakan adalah pedoman observasi dan wawancara.

a) Observasi

Observasi dilakukan, dengan mengamati secara langsung terhadap obyek penelitian khususnya pemanfaatan data rekam medis sensus harian rawat inap di Rumah Sakit Umum Muhammadiyah Ponorogo.

b) Wawancara

Wawancara yaitu cara yang digunakan jika sumber atau responden penelitian adalah manusia yang dilakukan secara langsung. Dengan diajukannya pertanyaan-pertanyaan untuk dijawab oleh responden.

\section{9) Pengumpulan Data}

a) Data Primer

Data primer adalah data yang diperoleh langsung dari subjek penelitian dengan alat pengukuran atau alat pengambil data, langsung pada subyek sebagai sumber informasi yang dicari (Saryono dan Mekar Dwi Anggraeni, 2013). Dalam penelitian ini data primer diperoleh dari observasi dan wawancara petugas analising reporting untuk mendapatkan data tentang pemanfaatan sensus harian rawat inap untuk pelaporan indikator pelayanan rawat inap Rumah Sakit Umum Muhammadiyah Ponorogo.

b) Data Sekunder

Data sekunder adalah data yang didapatkan dari sumber lain (Bustami, 2011). Menurut Saryono dan Mekar Dwi Anggraeni (2013), data sekunder adalah data yang diperoleh lewat pihak lain, tidak langsung diperoleh oleh peneliti dari subjek penelitian. Dalam penelitian ini data sekunder berasal dari pihak rumah sakit yaitu data sensus harian rawat inap Rumah Sakit Umum Muhammadiyah Ponorogo.

\section{0) Analisa Data}

Analisis yang digunakan adalah deskriptif yaitu memaparkan hasilhasil penelitian yang sesuai dengan keadaan sebenarnya dengan membandingkan teori-teori yang terkait dan selanjutnya ditarik suatu kesimpulan tanpa melakukan uji statistik (Arief, M. 2003)

\section{1)Etika Penelitian}

Beberapa prinsip dalam pertimbangan etik adalah bebas dari eksplotasi, bebas dari penderitaan, ada kerahasiaan dan responden bebas menolak masalah etik ditekankan pada:

a) Informed Consent (Lembar Persetujuan)

Responden yang memenuhi syarat akan diberikan penjelasan tentang maksud dan tujuan penelitian. Jika responden bersedia diteliti maka harus menandatangani lembar persetujuan yang disediakan oleh peneliti.

b) Anonimity (Tanpa Nama)

Untuk menjaga kerahasiaan responden, peneliti tidak mencantumkan nama responden pada lembar pengumpulan data.

c) Confidentility (Kerahasiaan )

Semua informasi maupun masalah-masalah dalam pengumpulan data yang telah diperoleh dari responden, dijamin kerahasiaannya oleh peneliti dan hanya kelompok data tertentu yang dilaporkan pada data hasil riset. 
(7) Dokter (Dokter Spesialis)

\section{HASIL PENELITIAN}

1) Pelayanan Rawat Inap terdapat

118 tempat tidur dengan

pembagian kelas sebagai berikut :

Tabel 2 Jumlah Tempat Tidur Di Rumah Sakit Umum Muhammadiyah Ponorogo

\begin{tabular}{|c|c|c|c|c|c|c|c|}
\hline \multirow[t]{2}{*}{ Kelas } & \multicolumn{6}{|c|}{ Jumlah Tempat Tidur } & \multirow{2}{*}{$\begin{array}{c}\text { Total } \\
\text { T.Tidur }\end{array}$} \\
\hline & A. dahlan & Fahruddin & Walidah & Mansur & Peri & $\begin{array}{l}\text { Icu- } \\
\text { Iccu }\end{array}$ & \\
\hline Superior & & 6 & 2 & 5 & & & 13 \\
\hline $\begin{array}{l}\text { Vip } \\
\text { (Standart) }\end{array}$ & 4 & & 2 & 1 & & & 7 \\
\hline Kelas I & 1 & 8 & 2 & 2 & & & 13 \\
\hline Kelas II & 11 & 5 & 4 & 4 & & & 24 \\
\hline $\begin{array}{l}\text { Kelas } \\
\text { III/Zaal }\end{array}$ & 8 & 10 & 9 & 19 & & & 46 \\
\hline Rri & & 2 & & & & & 2 \\
\hline Isoalsi & 1 & & & 2 & & & 3 \\
\hline Observasi & & & & & & & 0 \\
\hline Perinatologi & & & & & 4 & & 4 \\
\hline Icu-Iccu & & & & & & 6 & 6 \\
\hline Total & 25 & 31 & 19 & 33 & 4 & 6 & 118 \\
\hline
\end{tabular}

a. Fasilitas pemeriksaan penunjang antara lain :
(1) Laboratorium 24 Jam
(2) Farmasi 24 Jam
(3) Radiologi
(4) Instalasi Rawat Inap
(5) Instalasi Gizi
(6) Instalasi
Bedah
Sentral/Kamar Operasi

2) Kebijakan Rumah Sakit tentang sumber data Pelaporan Sensus Harian Rawat inap (SHRI)

$$
\text { Sesuai dengan Buku }
$$

Pedoman Penyelenggaraan

Rekam Medis Rumah Sakit

Umum Muhammadiyah Ponorogo disebutkan bahwa Rumah Sakit Umum Muhammadiyah Ponorogo 
melaksanakan pengolahan data sebagai pelaporan adalah Semua bentuk catatan, baik hasil rekapitulasi harian, maupun lembaran-lembaran form rekam medis merupakan bahan yang perlu diolah untuk selanjutnya dipakai sebagai bahan laporan Rumah Sakit. Sebelum dilakukan pengolahan, berkas-berkas rekam medis tersebut diteliti kelengkapan baik isi maupun jumlahnya. Rekapitulasi dari sensus harian diolah untuk menyiapkan laporan yang menyangkut kegiatan rumah sakit, sedangkan form-form rekam medis diolah untuk menyiapkan laporan inetrnal maupun eksternal.

3) Pihak yang mengelola Data Sensus Harian Rawat Inap (SHRI)

Sensus Harian Rawat Inap dikelola dan diisi oleh unit rekam medis dan ruang rawat inap Rumah Sakit Umum Muhammadiyah Ponorogo. Ruang rawat inap/bangsal adalah sebagai pihak yang mengisi Sensus Harian Rawat Inap (SHRI).

Berdasarkan observasi di lapangan dan wawancara pada petugas analising reporting, yang mengelola Sensus Harian Rawat Inap (SHRI) adalah unit rekam medis/analising reporting adapun kegiatannya sebagai berikut :

a. Petugas analising reporting menerima Sensus Harian Rawat Inap (SHRI) dari petugas rawat inap setiap hari jam 08.00 WIB setelah Kepala bangsal mengecek dan menandatangani Sensus Harian Rawat Inap

b. Mengindeks Data Sensus Ruangan berdasarkan Nomor Rekam Medis, Nama Pasien,
Umur, Jenis Kelamin, Tanggal masuk dan keluar, Lama Dirawat, Kelas ( I, II, III, VK, Superior, Dan VIP Standar), Jumlah Hari Perawatan, Pasien Meningal < 48 Jam dan Pasien Meningal > 48 Jam ke Komputer.

Tabel 3 Hasil Indeks Bangsal Siti

Walidah Bulan Mei 2019 di Rumah Sakit Umum

Muhammadiyah Ponorogo

\begin{tabular}{lccccccc}
\hline Kelas & I & II & III & VK & Superior & Standart & Total \\
\hline Pasien & 24 & 39 & 109 & 0 & 6 & 12 & 190 \\
$\begin{array}{l}\text { Jumlah Hari } \\
\text { Perawatan }\end{array}$ & 71 & 117 & 295 & 0 & 18 & 36 & 537 \\
$\begin{array}{l}\text { Pasien } \\
\begin{array}{l}\text { Meningal }< \\
\text { 48 Jam }\end{array}\end{array}$ & 0 & 0 & 0 & 0 & 0 & 0 & 0 \\
$\begin{array}{l}\text { Pasien } \\
\text { Meningal }> \\
\text { 48 Jam }\end{array}$ & 0 & 0 & 0 & 0 & 0 & 0 & 0 \\
\hline
\end{tabular}

Pada Bulan Mei 2019 bangsal Siti Walidah dikunjungi 190 pasien dengan pembagian kelas I, II , III, VK, Superior, VIP Standar dan menghasilkan hari perawatan berjumlah 537 hari perawatan sedangkan untuk pasien meningal $<48$ jam dan $>48$ berjumlah nol atau tidak ada pasien meningal.

c. Mendata Pasien Meningal, Rujuk, dan Atas Permintaan Sendiri (APS) brerdasarkan hasil observasi di bangsal Siti Walidah belum ada pasien Meningal, Rujuk, dan APS

d. Melakukan perekapan Sensus Harian Rawat Inap (SHRI) bangsal Siti Walidah ke Indikator Kinerja Rumah Sakit yang dilakukan pada akhir bulan Mei

e. Mengolah data Sensus Harian Rawat Inap (SHRI) menjadi beberapa indikator pelayanan diantaranya BOR, LOS, BTO, TOI, AVLOS, NDR dan GDR 


\section{Jurnal Delima Harapan $\mathbf{2 0 2 0}$}

4) Pengolahan Data Sensus Harian Rawat Inap (SHRI) untuk Pelaporan.

Data Sensus Harian Rawat Inap (SHRI) di Rumah Sakit Umum Muhammadiyah Ponorogo diperoleh dari setiap bangsal perawatan setelah itu dilanjutkan dengan rekapitulasi ke dalam Indikator Kinerja Rumah Sakit dan dijadikan sebagai dasar pembuatan Indikator Pelayanan Rawat Inap.

a. Mekanisme Pengolahan Data

Sensus Harian Rawat Inap (SHRI) bangsal Siti Walidah

(1) Data sensus bangsal Siti

Walidah bulan Mei tahun 2019 dientry ke komputer dan diolah Tabel 4. Data Rekapitualsi Jumlah Pasien Keluar Hidup dan Meningal Bangsal Siti Walidah Bulan Mei Tahun 2019 Rumah Sakit Umum Muhammadiyah Ponorogo.

\begin{tabular}{|c|c|c|c|c|}
\hline \multicolumn{3}{|c|}{ Jumlah Pasien Keluar } & \multirow{4}{*}{ Jumlah } & \multirow{4}{*}{$\begin{array}{l}\text { Jumlah } \\
\text { Pasien } \\
\mathrm{H}+\mathrm{M}\end{array}$} \\
\hline \multirow[t]{3}{*}{ Hidup } & \multicolumn{2}{|c|}{ Mati } & & \\
\hline & 48 & 48 & & \\
\hline & Jam & Jam & & \\
\hline 24 & 0 & 0 & 0 & 24 \\
\hline 39 & 0 & 0 & 0 & 39 \\
\hline 109 & 0 & 0 & 0 & 109 \\
\hline 6 & 0 & 0 & 0 & 6 \\
\hline 12 & 0 & 0 & 0 & 12 \\
\hline 190 & $\mathbf{0}$ & $\mathbf{0}$ & $\mathbf{0}$ & 190 \\
\hline
\end{tabular}

Tabel 5. Data Rekapitualsi Jumlah Tempat Tidur, Pasien dan Hari Perawatan Bangsal Siti Walidah Bulan Mei Tahun 2019 Rumah Sakit Umum Muhammadiyah Ponorogo

\begin{tabular}{lccc}
\hline Kelas & $\begin{array}{l}\text { Jumlah } \\
\text { TT }\end{array}$ & $\begin{array}{c}\text { Jumlah } \\
\text { Pasien }\end{array}$ & $\begin{array}{c}\text { Jumlah Hari } \\
\text { Perawatan }\end{array}$ \\
\hline Kelas I & 2 & 24 & 71 \\
Kelas II & 2 & 39 & 117 \\
Kelas III & 11 & 109 & 295 \\
Superior & 2 & 6 & 18 \\
$\begin{array}{l}\text { Vip } \\
\text { (Standart) }\end{array}$ & 2 & 12 & 36 \\
Total & $\mathbf{1 9}$ & $\mathbf{1 9 0}$ & $\mathbf{5 3 7}$
\end{tabular}

Hasil data Rekapitulasi pada bulan Mei Tahun 2019 yang akan digunakan pada perhitungan Indikator Pelayanan Rawat Inap bangsal Siti Walidah di Rumah Sakit Umum Muhammadiyah Ponorogo.

(2) Membuat Grafik/Tabel BOR, LOS, BTO, TOI, AVLOS, NDR dan GDR dari bangsal Siti Walidah Bulan Mei Tahun 2019

(3) Menggabungkan

Grafik/Tabel dalam tabel keseluruhan sehingga akan dapat menghasilkan Indikator Kinerja Rumah Sakit Umum Muhammadiyah Ponorogo.

b. Tata Cara Pengisian Formulir

Sensus Harian Rawat Inap (SHRI) Sensus Harian Rawat Inap (SHRI) Rumah Sakit Umum Muhammadiyah Ponorogo. belum ada Petunjuk Teknis pengisian formulir. Berdasarkan hasil observasi dan wawancara kepada petugas analising reporting tentang pengisian Sensus Harian Rawat Inap (SHRI) di Rumah Sakit Umum Muhammadiyah 
Ponorogo pada form keluar, masuk, penderita yang dipindahkan ke ruang lain, penderita pindahan dari ruang lain, meninggal < 48 jam, meningga $1 \geq 48$ jam, berisi sama yaitu nomor rekam medis, nama penderita, bagian atau kelas perawatan.

c. Manfaat Pengisian

Berdasarkan hasil observasi dan wawancara pada petugas analising reporting manfaat Sensus Harian Rawat Inap (SHRI) di Bangsal Siti Walidah Rumah Sakit Umum Muhammadiyah Ponorogo sebagai berikut :

(1) Untuk mengetahui jumlah pasien masuk yang berjumlah 190 pasien dan pasien keluar bangsal dengan kondisi meningal yang berjumlah Nol atau tidak ada pasien

(2) Untuk mengetahui tingkat penggunaan tempat tidur di bangsal Siti Walidah dengan jumlah $91,17 \%$ yang menunjukan penggunaan tempat tidur lebih tinggi dari nilai ideal penggunaan tempat tidur yang disarankan $75 \%$ - $85 \%$. (Sudra, 2010)

(3) Untuk menghitung penyediaan sarana atau fasilitas pelayanan kesehatan untuk waktu kedepannya.

\section{PEMBAHASAN}

1) Kebijakan Rumah Sakit Tentang Sumber Data Pelaporan Sensus Harian Rawat Inap (SHRI).

Rumah Sakit Umum Muhammadiyah Ponorogo sudah memiliki kebijakan tentang pemanfaatan data Sensus Harian Rawat Inap (SHRI) yang tertulis dalam Buku Pedoman Penyelenggaraan Rekam Medis yang dibuat oleh pihak Rumah Sakit
Umum Muhammadiyah Ponorogo yang menyatakan bahwa sensus harian diolah untuk menyiapkan laporan yang menyangkut kegiatan rumah sakit, sedangkan form-form rekam medis diolah untuk menyiapkan laporan inetrnal maupun eksternal Dari petunjuk kebijakan yang tertulis dalam Buku Pedoman Penyelenggaraan Rekam Medis Rumah Sakit Umum Muhammadiyah Ponorogo semua pelaporan sudah dibuat dan dilaksanakan oleh pihak rumah sakit.

2) Pihak yang mengelola Data Sensus Harian Rawat Inap (SHRI)

Sensus Harian Rawat Inap (SHRI) Rumah Sakit Umum Muhammadiyah Ponorogo dikelola oleh petugas analising reporting. Hal itu sudah sesuai dengan Prosedur Tetap Rumah Sakit Umum Muhammadiyah Ponorogo tentang Pengumpulan Sensus Harian Rawat Inap Menurut observasi di lapangan dan wawancara pada petugas analising reporting hal tersebut diserahkan kepada Kepala Bagian Rekam Medis untuk menunjuk anggotanya sesuai tugas pokok masing-masing dalam pelaksanaan kegiatannya.

Menurut DepKes, 2006 tentang bahwa tugas pokok analising reporting salah satunya adalah mengumpulkan data kegiatan rumah sakit dari sensus harian yang dicatat oleh unit pelayanan pencatatan data kegiatan rumah sakit, sensus harian sebagai dasar penyusunan laporan kegiatan rumah sakit

3) Pengolahan Data Sensus Harian Rawat Inap (SHRI) untuk Pelaporan Indikator Pelayanan Rawat Inap Adapun Prosedur Tetap Rumah Sakit Umum Muhammadiyah Ponorogo tentang Pengumpulan dan 
Pengolahan Sensus Harian Rawat Inap hanya memuat tentang teknis pengumpulan dan pengolahan Sensus Harian Rawat Inap (SHRI), dalam prosedur tersebut isinya juga belum memuat seluruh teknis mekanisme pengisian Sensus Harian Rawat Inap (SHRI).

Prosedur Tetap sendiri adalah suatu petunjuk pelaksanaan prosedur yang tertulis sebagai panduan standarisasi dalam menjalani suatu kegiatan. Prosedur Tetap akan sangat membantu suatu unit pelaksana kegiatan pelayanan untuk menjalankan segala aktifitas pelayanan agar tetap dapat menjaga mutu pelayanannya. Agar lebih baik lagi kalau adanya prosedur tetap memuat seluruh mekanisme dan tujuan, manfaat, pelaksana, penanggung jawab, pengertian, kebijakan, prosedur teknis yang runtun dan jelas sehingga dapat menjadi pedoman/panduan dalam melaksanakan pengisian untuk memperoleh data yang valid dan sesuai dengan keadaan sebenarnya.

Data Sensus Harian Rawat Inap (SHRI) Rumah Sakit Umum Muhammadiyah diolah melalui beberapa tahapan. Sesuai hasil kegiatan data Sensus Harian Rawat Inap (SHRI) diterima oleh petugas analising reporting lalu dilakukan perekapan setelah itu dilakukan pengolahan data sesuai kebutuhan pembuatan indikator pelayanan rawat inap. Adapun data yang digunakan oleh petugas analising reporting yang diambil dari Sensus Harian Rawat Inap (SHRI) untuk pembuatan Indikator Pelayanan Rawat Inap hanya Hari Perawatan dan Lama Dirawat yang selanjutnya digunakan sebagai dasar penghitungan BOR (Bed Occupancy Rate), AvLOS
(Average Length Of Stay), TOI (Turn Over Interval). Adapun BTO (Bed Turn Over) tidak bersumber dari Sensus Harian Rawat Inap (SHRI) melainkan dari register pasien rawat inap dan data ruang rawat inap. Dari 3 parameter diatas BOR (Bed Occupancy Rate), AvLOS (Average Length Of Stay), TOI (Turn Over Interva), diolah dengan menggunakan rumus berdasar pada buku Ery R. 2009. Statistik Rumah Sakit Untuk Pengambilan Keputusan.

Menurut observasi di lapangan dan wawancara pada petugas analising reporting pemanfaatan data sensus harian tidak dilakukan secara maksimal dikarenakan tidak disiplinnya pengisian dan penyerahan Sensus Harian Rawat Inap (SHRI) dikarenakan tidak ada prosedur tetap dan petunjuk teknis pengisian yang memuat seluruh kegiatan yang harus dilakukan oleh petugas bangsal rawat inap yang menyebabkan isi dari sensus harian tidak sesuai dengan keadaan sebenarnya seperti contoh :

a. Data keterangan pasien pulang yang dicatat pada Sensus Harian Rawat Inap (SHRI) tidak terisi, sehingga menyulitkan penghitungan karena pasien pulang dengan kondisi yang tidak diketahui.

b. Hari perawatan yang tidak diisi lengkap sehingga dapat mempengaruhi dalam penghitungan BOR (Bed Occupancy Ratio) karena dalam rumus BOR (Bed Occupancy Ratio) terdapat jumlah Hari Perawatan.

c. Jumlah tempat tidur jika terjadi perubahan tidak lansung ditulis pada Sensus Harian Rawat Inap (SHRI), sehingga petugas analising reporting harus 
menanyakan ke ruang rawat inap/bangsal tentang jumlah tempat tidur hal menyulitkan penghitungan efisiensi tempat tidur

Petugas harus mencari sumber data lain seperti register pasien rawat inap untuk menjadi dasar sumber data pelaporan untuk dicocokkan dengan Sensus Harian Rawat Inap (SHRI), hal ini mendorong petugas analising reporting lebih memanfaatkan data di dalam register pasien rawat inap dari pada Sensus Harian Rawat Inap (SHRI) karena data register pasien rawat inap lebih sesuai dengan keadaan sebenarnya.

Semua data Sensus Harian Rawat Inap (SHRI) di isi dan di hitung semua tapi beberapa data diisi tidak sesuai keadaan aslinya. Maka pada pelaksanaannya semua hasil data Sensus Harian Rawat Inap (SHRI) tidak dimanfaatkan maksimal. Maka perlu diadakannya sosialisasi petunjuk teknis penulisan/pengisian dan prosedur tetap tentang Sensus Harian Rawat Inap (SHRI) untuk petugas rawat inap utamanya perawat atau bidan dalam mekanisme pelaksanaannya. Sehingga pembuatan, penyerahan, perekapan, Sensus Harian Rawat Inap dilaksanakan petugas setiap hari dan sesuai keadaan aslinya agar tidak perlu lagi mencocok kan data dengan register pasien rawat inap dan tidak menambah beban kerja petugas, sesuai kebijakan Rumah Sakit dan prosedur tetap yang ada.

\section{Kesimpulan}

1) Kebijakan Rumah Sakit Tentang Sumber Data Pelaporan Sensus Harian Rawat Inap (SHRI).

Sesuai dengan Buku Pedoman Penyelenggaraan Rekam Medis Rumah Sakit Umum Muhammadiyah Ponorogo disebutkan bahwa Rekapitulasi dari sensus harian diolah untuk menyiapkan laporan yang menyangkut kegiatan rumah sakit.

2) Pihak yang Mengolah Data Sensus Harian Rawat Inap (SHRI)

Pihak yang mengolah Data Sensus Harian Rawat Inap (SHRI) di serahkan kepada Kepala Bagian Rekam Medis yang juga bertugas sebagai petugas analising reporting atau menunjuk anggotanya sesuai tugas pokok masing-masing dalam pelaksanaan kegiatannya.

3) Pengolahan Data Sensus Harian Rawat Inap (SHRI) Untuk Pelaporan Indikator Pelayanan Rawat Inap

Pengolahan data Sensus Harian Rawat Inap (SHRI) di Rumah Sakit Umum Muhammadiyah Ponorogo dapat menghasilkan pelaporan indikator rawat inap yaitu BOR (Bed Occupancy Rate), AvLOS (Average Length Of Stay), TOI (Turn Over Interval). Untuk BTO (Bed Turn Over) dan indikator pelayanan rawat inap yang lain tidak di hitung berdasarkan Sensus Harian Rawat Inap (SHRI) karena data sensus harian belum dimanfaatkan secara maksimal dikarenakan kurang disiplinnya pengisian dan penyerahan Sensus Harian Rawat Inap (SHRI) serta tidak ada adanya petunjuk pengisian Sensus Harian Rawat Inap (SHRI 
Saran

1) Sebaiknya membuat Prosedur Tetap dan Petunjuk yang mencakup seluruh kegiatan mekanisme pelaksanaan Sensus Harian Rawat Inap (SHRI),sehingga petugas bangsal/ruang rawat inap dapat melaksanakan pembuatan Sensus Harian Rawat Inap (SHRI) secara benar dan menghasilkan data yang akurat untuk dimanfaatkan dalam penghitungan indikator pelayanan rawat inap (Usulan prosedur tetap pada pengisian Sensus Harian Rawat Inap pada lampiran 13)

2) Perlu diadakannya sosialisasi petunjuk teknis penulisan/pengisian dan prosedur tetap tentang Sensus Harian Rawat Inap (SHRI) untuk petugas rawat inap utamanya perawat atau bidan dalam mekanisme pelaksanaannya.

3) Sebaiknya pembuatan, penyerahan, perekapan, Sensus Harian Rawat Inap dilaksanakan petugas setiap hari dan sesuai keadaan aslinya agar tidak perlu lagi mencocok kan data dengan register pasien rawat inap dan tidak menambah beban kerja petugas, sesuai kebijakan Rumah Sakit dan prosedur tetap yang ada.

4) Sebaiknya petugas rawat inap/bangsal (perawat/bidan) memasukkan data secara benar sehingga petugas analising reporting bisa memanfaatkan data Sensus Harian Rawat Inap (SHRI) untuk

a. Sebagai sumber data dan mempermudah pembuatan pelaporan indikator pelayanan rawat inap seperti:
(1) AvLOS (Average Length Of Stay)
(2) BOR (Bed Occupancy Rate)
(3) BTO (Bed Turn Over)
(4) TOI (Turn Over Interval)
(5) NDR (Net Death Rate)
(6) GDR (Gross Death Rate)
(7) Newborn death rate
(8) Maternal death rate

b. Sebagai sumber data keadaan Morbiditas Pasien Rawat Inap

c. Sebagai sumber data bulanan

(1) Pengunjung Rumah Sakit

(2) Daftar 10 Besar Penyakit Rawat Inap

\section{DAFTAR PUSTAKA}

Agung kurniawan. 2003. Analisis pemanfaatan data sensus harian rawat inap untuk pelaporan indikator pelayanan rawat inap di rumah sakit umum daerah $d r$. Soeroto ngawi

Arier, M. 2003. Pengantar metodologi penelitian untuk ilmu kesehatan. Surakarta : sebelas Maret University Press. Hal 8,43,53-4

Bustami. 2011. Penjamin Mutu Pelayanan Kesehatan dan Akseptabilitasnya. Jakarta : Erlangga

Depkes RI. 2003. Sistem Informasi Rumah Sakit di Indonesia (sistem Pelaporan Rumah Sakit (Sistem Pelaporan Rumah Sakit Revisi V). Jakarta. hal. 2-8

Depkes RI Tahun. 2005. Buku Petunjuk Pengisian, Pengolahan Dan Penyajian Data Rumah Sakit. Jakarta DITJENYANMED

Depkes RI tahun 2006. Pedoman Penyelengaraan Dan Prosedur Rekam Medis Rumah Sakit Di Indonesia. Revisi 2. Jakarta : Dirjen 
Bina Pelayanan Medik

Departemen Kesehatan RI

I gusti dkk. 2013 Tinjauan pelaksanaan

\begin{tabular}{|c|c|c|}
\hline sensus & harian & rawat \\
\hline inap,rumal & sakit & итит \\
\hline $\begin{array}{l}\text { daerah } \\
\text { boyolali }\end{array}$ & pandan & arang \\
\hline
\end{tabular}

Peraturan menteri kesehatan No. 1171/menkes/per/VI/2011 tentang sistem informasi rumah sakit.

Peraturan menteri kesehatan No. 147 Tahun $2010 \quad$ tentang Perizinan Rumah sakit Soekidjo noto admojo (2010) metodologi penelitian kesehatan. Rineka cipta jakarta

Rustiyanto .2010 .Statistik Rumah Sakit Untuk Pengambilan Keputusan

Saryono dan Mekar Dwi Anggraeni. 2013. Metodologi Penelitian Kuantitatif dan Kualitatif dalam Bidang Kesehatan. Yogyakarta : Nuha Medika.

Shofari B, 2002 . Modul Pembelajaran Pengelolaan Rekam Medis Dan Dokumentasi Rekam Medis. PSRK_01. Semarang : PORMIKI.

(Tidak

Dipublikasikan)

Sudra R I. 2010. Statistik Rumah Sakit Yogyakarta :Graha Ilmu. Hal 2-57

Sugiyono. 2016. Metode Penelitian Kuantitatif, Kualitatif dan $R \& D$. Bandung: PT Alfabet.

Undang-undang. RI. no 44.tahun 2009.tentang rumah sakit 